\title{
On the variations of the resistance of electrical machines with their velocity
}

\section{M.E. Lacoine}

To cite this article: M.E. Lacoine (1882) On the variations of the resistance of electrical machines with their velocity, Philosophical Magazine Series 5, 13:78, 76-76, DOI:

10.1080/14786448208627149

To link to this article: http://dx.doi.org/10.1080/14786448208627149

曲 Published online: 28 Apr 2009.

Submit your article to this journal $₫$

Џll Article views: 2

Q View related articles $₫$ 
ON THE VARTATIONS OF THE RESISTANCE OF ELECTRICAL

MACHINES WITH THEIR VELOCITY. BY M. E. LACOINE.

It is known that the resistance of magneto- and dynamoelectrical machines is not constant, but increases with their velocity. The experiments of which I am about to give an account to the Academy afford ground for thinking that these variations of the resistance are to be explained by those of the contact between the movable commutator and the rubber-springs.

I employed a copper cylinder 5 centim. in diameter, with longitudinal grooves resembling the insulating ones of a Gramme's commutator. Upon this cylinder, at two diametrically opposite points, rub two steel springs which form the terminations of the two extremities of a circuit comprising a battery, a telephone, and a galvanometer to measure the resistances. The resistance of the circuit was :-

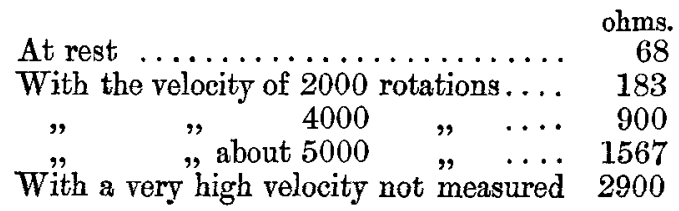

The sound given by the telephone was the louder and shriller the greater the velocity.

In this first series of experiments every spring touched the cylinder over a space of three grooves; on making them touch over a greater extent (eight grooves), less sensible variations are obtained.

For each velocity the resistance diminishes when the pressure of the spring is increased. It is possible even to reach a pressure sufficient to suppress all microphonic effect and stop all sound in the telephone.

I have since modified the apparatus, and substituted for the fluted cylinder one of the same diameter but with its surface smooth. I obtained the same effects with a very little higher velocity. Instead of making the springs touch on the cylindrical portion, I caused them to press upon the plane lateral portion; the same results were observed.

The measurements which I have taken give me reason to believe that, for one and the same pressure of the springs, the increase of the resistance is proportional to the cube of the velocity; but it would be necessary to repeat these experiments with means which were wanting to me at Constantinople, in order to be assured of a constant velocity and to measure it exactly.

I will conclude by saying that with the telephone a more intense sound is heard when the intensity of the current is less; hence I conclude that the sound given by a telephone placed in the circuit of a Gramme machine is not due merely to the undulatory variations of the current, but also to the microphonic effect of the commutator.-Comptes Rendus de l'Academie des Sciences, December 5, 1881, t. xciii. pp. 958, 959. 